\title{
Feeding Tube Complication
}

National Cancer Institute

\section{Source}

National Cancer Institute. Feeding Tube Complication. NCI Thesaurus. Code C122445.

Any problem with a feeding tube or its site of insertion. 